\title{
EFEITO DO TIAMETOXÃ NA PRODUTIVIDADE DO FEIJOEIRO $^{1}$
}

\author{
André Luiz Lourenção ${ }^{1}$ \\ Sérgio Augusto Morais Barbonell ${ }^{2}$ \\ Giuliana Etore do Valle ${ }^{3}$
}

\section{RESUMO}

Avaliou-se o efeito do Tiametoxã na produtividade de três cultivares de feijoeiro (IAC-Carioca Eté, IAC-Carioca e IAPAR 72), em quatro níveis de aplicação: a) testemunha (nível 0); b) tratamento de sementes com Cruiser (TS); c) TS e uma aplicação foliar de Actara aos 14 dias (TS+AC); d) TS mais duas aplicações de Actara, aos 14 e aos 28 dias (TS+AC+AC). Foi conduzido um experimento em duas épocas (fevereiro-maio e setembro-dezembro de 2001) em Ribeirão Preto, SP. Utilizou-se um delineamento de 5 blocos ao acaso, com doze tratamentos. A interação época $x$ tratamento foi significativa para produtividade. $\mathrm{Na}$ primeira época não houve diferença entre os tratamentos. Na segunda, as maiores produtividades foram de IAC-Carioca $+\mathrm{TS}+\mathrm{AC}+\mathrm{AC}$, IACCarioca + TS + AC, IAC-Carioca + TS, IAPAR 72+TS+AC e IAPAR $72+\mathrm{TS}$, que diferiram de todos os tratamentos envolvendo IAC-Carioca Eté. Considerando-se cada cultivar e seus quatro níveis de aplicações de tiametoxã, verifica-se que não houve diferença entre os níveis, o que mostra que a aplicação do neonicotinóide não influiu na produtividade.

\section{ABSTRACT}

\section{EFFECT OF THIAMETOXAN ON DRY BEAN YIELD}

The effect of Thiametoxam on dry bean yield was evaluated under field conditions, at Ribeirão Preto, State of São Paulo, Brazil. An et al., 
experiment was carried out in 2001, in two seasons: February-May and September-December. A complete randomized block design with 12 treatments and 5 replications was used. The cultivars IAC-Carioca Eté, IAC- Carioca and IAPAR 72 were submitted to four levels of thiametoxam: a) check (level 0); b) seed treatment with $\left.\operatorname{Cruiser}^{\hat{a}}(\mathrm{ST}) ; \mathrm{c}\right)$ ST plus foliar application of Actara ${ }^{a}, 14$ days after germination (ST + AC); d) ST plus two foliar application of Actara ${ }^{a}, 14$ and 28 days after germination $(\mathrm{ST}+\mathrm{AC}+\mathrm{AC})$. There was a significant interaction between season and treatment for yield. In the first season, there was no difference among treatments. In the second season, the treatments IACCarioca $+\mathrm{TS}+\mathrm{AC}+\mathrm{AC}$, IAC-Carioca+TS $+\mathrm{AC}$, IAC-Carioca+TS, IAPAR $72+\mathrm{TS}+\mathrm{AC}$ and IAPAR $72+\mathrm{TS}$ presented higher yield when compared to all treatments with IAC-Carioca Eté. However, there were no differences among the thiametoxam levels within each cultivar, indicating that the insecticide has no effect on yield.

\section{INTRODUÇÃO}

O feijão é um alimento de extrema importância para o povo brasileiro, tendo a produção em nosso país alcançado mais de 3 milhões de toneladas em 1999/2000 (Agrianual, 2001). Trata-se de uma cultura com diversos problemas fitossanitários, destacando-se entre eles insetos sugadores e desfolhadores (Gallo et al., 2002) e doenças fúngicas, bacterianas e viróticas (Bianchini et al., 1997). Dentre as doenças, assume especial importância o mosaico dourado, considerado fator limitante de produção em diversas regiões do país (Costa, 1975) e transmitido pela mosca branca Bemisia tabaci (Costa, 1965). Para controle do mosaico dourado, tem-se utilizado principalmente o cultivo em áreas delimitadas associado a época adequada de plantio, situação em que o vetor e a doença estão praticamente ausentes. Enfocando-se o controle químico, uma alternativa em áreas de risco é o uso de inseticidas sistêmicos, cuja proteção contra o vetor deve se estender pelo menos da emergência das plântulas até o florescimento, período em que as plantas são mais afetadas quando infectadas por esse vírus.

Os neonicotinóides, inseticidas de ação sistêmica, vêm sendo utilizados no Brasil com sucesso em diversas culturas para controle de diferentec ecnériec de incetne cuoadnres /Renvenoa of al 1998. Rntton 
et al., 1998; Silva \& Papa, 1998), incluindo-se a mosca branca (Martins \& Nakamura, 2000). O Tiametoxã é um inseticida desse grupo, controlando um amplo espectro de insetos através de contato e sugestão, em baixas concentrações (Lawson et al., 1997, apud Ayyappath et al., 2000). Vem sendo considerado similar ao Imidaclopride na estrutura e no modo de ação (Ayyappath et al., 2000), embora haja indicação de que possam haver diferenças no modo de ação entre neonicotinóides de maneira geral, principalmente entre Tiametoxã e imidaclopride (Wiesner et al., 2000).

Devido a sua eficiência contra a mosca branca, o tiametoxã pode ser incluído no manejo de pragas do feijoeiro tanto no plantio (tratamento de sementes) como durante o ciclo das plantas. Como tem-se aventado a possibilidade de o tiametoxã induzir efeito fitotônico além do controle de pragas, objetivou-se no presente trabalho avaliar a produtividade de três cultivares de feijoeiro quando submetidos a diferentes níveis desse inseticida.

\section{MATERIAL E MÉTODOS}

Um experimento foi instalado na Estação Experimental de Ribeirão Preto, pertencente ao IAC, em 2001, em duas datas: 21/2 e 11/ 9. Utilizou-se delineamento de 5 blocos ao acaso, com doze tratamentos (Tabela 1). Os três cultivares avaliados (IAC-Carioca-Eté, IAC-Carioca e IAPAR 72) foram submetidos a quatro níveis de tratamento com Tiametoxã: a) testemunha (nível 0); b) tratamento de semente (TS) (3ml Cruiser $/ \mathrm{kg}$ semente); c) TS e aplicação de Tiametoxã ( $100 \mathrm{~g}$ Actara/ha) 14 dias após a germinação; d) TS e aplicação de Tiametoxã aos 14 e 28 dias após germinação. Cada parcela constou de quatro linhas de $5 \mathrm{~m}$, espaçadas $0,5 \mathrm{~m}$ entre si. A adubação foi realizada no sulco, com a fórmula 8-28-16, na base de $200 \mathrm{~kg} / \mathrm{ha}$, e a cobertura um mês após, com sulfato de amônio, também a $200 \mathrm{~kg} / \mathrm{ha}$. O estande aproximado foi de dez plantas por metro linear na primeira época e de doze na segunda. A fim de minimizar a influência de pragas e doenças na produtividade, realizaramse aplicações de inseticidas (deltametrina, permetrina), acaricida (abamectim) e fungicida (tebuconazole) em toda a gleba experimental quando da incidência desses agentes. Por ocasião da completa maturação 
(15/5 E 10/12), colheram-se as plantas dos quatro metros centrais das duas linhas centrais. Para análise estatística, os dados de produção não foram transformados. Efetuou-se análise de variância por experimento e conjunta, sendo as médias comparadas pelo teste de Tukey $(\mathrm{P}<0,05)$.

\section{RESULTADOS E DISCUSSÃO}

As análises estatísticas referentes às avaliações de produtividade

Tabela 1. Análises da variância individual por época e conjunta das avaliações de produtividade $(\mathrm{kg} / \mathrm{ha})$ de três cultivares de feijoeiro submetidas a quatro níveis de aplicação de thiamethoxam, em duas épocas de plantio. Ribeirão Preto, SP, 2001. $(n=5)$

\begin{tabular}{|c|c|c|c|c|c|}
\hline Avaliaçāo & Causas da variação & GL & SQ & F & Prob $>$ F \\
\hline \multirow{5}{*}{$\begin{array}{l}\text { Produtividade } \\
\text { Fev/Mai } 2001\end{array}$} & Blocos & 4 & $467.510,4$ & $2,38^{\mathrm{nt}}$ & 0,0661 \\
\hline & Tratamentos & 11 & $754.270,8$ & $1,40^{\circ \prime}$ & 0.2088 \\
\hline & Resíduo & 44 & $2.161 .302,1$ & & \\
\hline & Total & 59 & $3,383.083,3$ & & \\
\hline & $\mathrm{CV}=12,5 \%$ & & & & \\
\hline \multirow{5}{*}{$\begin{array}{l}\text { Produtividade } \\
\text { Set/Dez } 2001\end{array}$} & Blocos & 4 & $3.819 .619,8$ & $13,02 * *$ & 0,0001 \\
\hline & Tratamentos & 11 & $9.083 .632,8$ & $11,26^{* *}$ & 0.0001 \\
\hline & Resíduo & 44 & $3.228 .255,2$ & & \\
\hline & Total & 59 & $16.131 .507,8$ & & \\
\hline & $\mathrm{CV}=13,6 \%$ & & & & \\
\hline \multirow{7}{*}{$\begin{array}{l}\text { Análise } \\
\text { conjunta das } \\
\text { Épocas }\end{array}$} & Blocos (Época) & 8 & $4.287 .130,2$ & $8,75^{* *}$ & 0,0001 \\
\hline & Tratamentos & 11 & $4.779 .764,3$ & $7,09 * *$ & 0,0001 \\
\hline & Época & 1 & $1.532 .845,0$ & $25,03 * *$ & 0,0001 \\
\hline & Tratamento X Época & 11 & $5.058 .139,3$ & $7,51^{* *}$ & 0,0001 \\
\hline & Resíduo & 88 & $5.389 .557,3$ & & \\
\hline & Total & 119 & $21.047 .436,2$ & & \\
\hline & $\mathrm{CV}=13,2 \%$ & & & & \\
\hline
\end{tabular}


de feijoeiro acusaram diferenças significativas entre os tratamentos apenas para a segunda época (Tabelas $1 \mathrm{e} 2$ ).

Na primeira época de plantio, houve ocorrência de crisomelídeos desfolhadores (Diabrotica speciosa e Cerotoma sp.) na fase vegetativa das plantas, sendo feitas aplicações de Deltametrina (13/3) e de Permetrina (20/3) quando os níveis de desfolha atingiram ao redor de $5 \%$. Na fase reprodutiva houve incidência do ácaro branco (Polyphagotarsonemus latus), controlado com aplicação de Abamectim. Não foram observadas plantas com sintomas de mosaico dourado, sendo baixa a infestação da mosca branca $B$. tabaci. Em amostragem realizada em toda a área experimental na fase de enchimento de grãos, em que se coletaram três folíolos por parcela, obteve-se média de 0,012 ovos + ninfas $/ \mathrm{cm}^{2}$. Na segunda época de plantio, não houve necessidade de controle de insetos desfolhadores. Realizou-se uma aplicação de tebuconazole para controle de mancha-angular (florescimento) e uma de abamectim para ácaro branco (início de formação de vagens). Também neste segundo plantio não foram observadas plantas com sintomas de mosaico dourado. Utilizando-se amostragem idêntica ao do primeiro plantio, encontraram-se apenas cinco ovos e uma ninfa de mosca branca em toda a área experimental, indicando baixa infestação do inseto.

Com relação à produtividade (Tabela 1), a interação época $x$ tratamento foi significativa, o que pode ser atribuído a variações climáticas em associação com diferentes potenciais das cultivares em função da época de plantio. Na primeira época, as médias variaram desde $1557,5 \mathrm{~kg} / \mathrm{ha}$ (IAC-Carioca + Cruiser) até 1932,5 (IAC-Carioca + Cruiser + Actara aos 14 e 28 dias), embora não tenham sido detectadas diferenças significativas entre os tratamentos. $\mathrm{Na}$ segunda época, as maiores produtividades foram de IAC-Carioca $+\mathrm{C}+\mathrm{A}+\mathrm{A}$, IAC-Carioca $+\mathrm{C}+$ A, IAC-Carioca + C, IAPAR $72+\mathrm{C}+\mathrm{A}+\mathrm{A}$ e IAPAR $72+\mathrm{C}$, que diferiram significativamente de todos os tratamentos envolvendo IACCarioca-Eté. Desta forma, verifica-se a ocorrência de um grupo abrangendo as cultivares IAC-Carioca e IAPAR-72, com, à exceção de IAPAR-72+ C + A, três níveis de aplicação de tiametoxã, e um grupo envolvendo IAC-Carioca-Eté, com os quatro níveis. Isso pode ser devido ao fato de os cultivares apresentarem diferentes produtividades em função da época de plantio (Pompeu et al., 1999; Carbonell et al., 2000; 
Carbonell et al., 2001). Considerando-se isoladamente cada cultivar e seus quatro níveis de Tiametoxã, verifica-se que não houve diferença significativa entre os níveis, indicando que a aplicação do neonicotinóide não influiu na produtividade. Todavia, observa-se uma tendência, em todos os cultivares, de os tratamentos com tiametoxã apresentarem valores absolutos maiores de produtividade. Assim, torna-se desejável a realização de novas pesquisas, com a utilização de outras doses e outras

Tabela 2. Produtividade $(\mathrm{kg} / \mathrm{ha})$ de três cultivares de feijoeiro submetidas a quatro níveis de aplicação de tiametoxã, em duas épocas de plantio. Ribeirão Preto, SP, 2001. $(n=5)$

\begin{tabular}{llll}
\hline Tratamento & \multicolumn{3}{c}{ Ṕrodutividade $^{1}$} \\
\cline { 2 - 4 } & Fev-Mai 2001 Fev-Mai 2001 & Média \\
\hline IAC-Carioca+C+A+A & $1932,5 \mathrm{a}$ & $2497,5 \mathrm{a}$ & 2215,0 \\
IAC-Carioca+C+A & $1900,0 \mathrm{a}$ & $2377,5 \mathrm{a}$ & 2138,7 \\
IAPAR 72+C+A+A & $1797,5 \mathrm{a}$ & $2417,5 \mathrm{a}$ & 2107,5 \\
IAPAR 72+C & $1645,0 \mathrm{a}$ & $2317,5 \mathrm{a}$ & 1981,2 \\
IAPAR 72+C+A & $1795,0 \mathrm{a}$ & $2087,5 \mathrm{ab}$ & 1941,2 \\
IAC-Carioca+C & $1557,5 \mathrm{a}$ & $2225,0 \mathrm{a}$ & 1891,2 \\
IAPAR 72 & $1657,5 \mathrm{a}$ & $2092,5 \mathrm{ab}$ & 1875,0 \\
IAC-Carioca & $1637,5 \mathrm{a}$ & $1930,0 \mathrm{ab}$ & 1783,7 \\
IAC-Carioca Eté+C+A & $1862,5 \mathrm{a}$ & $1575,0 \mathrm{bc}$ & 1718,7 \\
IAC-Carioca Eté+C & $1850,0 \mathrm{a}$ & $1540,0 \mathrm{bc}$ & 1695,0 \\
IAC-Carioca Eté+C+A+A & $1790,0 \mathrm{a}$ & $1517,5 \mathrm{bc}$ & 1653,7 \\
IAC-Carioca Eté & $1765,0 \mathrm{a}$ & $1325,0 \mathrm{c}$ & 1545,0 \\
\hline Média & $1765,8 \mathrm{~B}$ & $1991,9 \mathrm{~A}$ & 1878,8 \\
CV & $12,5 \%$ & $13,6 \%$ & $13,6 \%$ \\
\hline
\end{tabular}

'Médias seguidas de mesma letra, minúscula na coluna e maiúscula na linha, não diferem significativamente entre si pelo teste de Tukey $(\mathrm{P}<0,05)$. ${ }^{2} \mathrm{C}=$ Cruiser (tratamento de semente); $\mathrm{A}=$ Actara (aplicação aos 14 dias após emergência); A + A
(aplicação de Actara aos 14 e aos 28 dias após emergência). 
plantas de interesse econômico para se avaliar possível efeito fitotônico do tiametoxã que possa influenciar positivamente a produtividade.

\section{CONCLUSÃO}

Para as condições agroecológicas em que foi conduzida a experimentação, a aplicação de Tiametoxã nos níveis avaliados (tratamento de semente; tratamento de semente mais aplicação aos 14 dias da emergência das plântulas, e tratamento de semente mais duas aplicações, aos 14 e 28 dias da emergência das plântulas) nos cultivares de feijoeiro IAC-Carioca, IAC-Carioca Eté e IAPAR 72 não influenciou a produtividade.

\section{REFERÊNCIAS BIBLIOGRÁFICAS}

AGRIANUAL, 2001. Anuário da Agricultura Brasileira. FNP Consultoria e Comércio, São Paulo. 545p.

AYYAPPATH, R.; POLAVARAPU, S.; MCGUIRE, M.R., 2000.

Effectiveness of Thiamethoxam-Coated Spheres Against Blueberry Maggot Flies (Diptera: Tephritidae). J. Econ. Entomol., 93:14731479.

BENVENGA, S.R., SILVA, J.L.; PAIVA, P.E.B.; GRAVENA, R.;

GRAVENA, S., 1998. Inseticidas Mais Eficientes no Controle das

Cigarrinhas Acrogonia gracilis, Dilobopterus costalimai e

Oncometopia facialis em Citros. In: CONGRESSO BRASILEIRO

DE ENTOMOLOGIA, 17., Rio de Janeiro, 1998. Resumos. Rio de Janeiro, livro 1, p.372.

BIANCHINI, A., MARINGONI, A.C.; CARNEIRO, S.M.T.P., 1997.

Doenças do Feijoeiro (Phaseolus vulgaris L.). In: KIMATI, H.; AMORIM, L.; BERGAMIN FILHO, A.; CAMARGO, L.E.A.; REZENDE, J.A.M. (eds.). Manual de Fitopatologia Doenças das Plantas Cultivadas. São Paulo: Ceres, vol.2. p.375-405.

BOTTON, M.; KOVALESKI, A.; BRAGHINI, L.; BANDIERA, V., 1998. Avaliação de Inseticidas Visando ao Controle da Filoxera 
da Videira Viteus vitifoliae (Hemiptera, Phylloxeridae). In: CONGRESSO BRASILEIRO DE ENTOMOLOGIA, 17., Rio de Janeiro, 1998. Resumos, Rio de Janeiro, livro 1, p.379. CARBONELL, S.A.M.; PINZAN, N.R.; SANNAZZARO, A.M., 2000.

Feijão: Sistema de Avaliação de Cultivares para o Estado de São Paulo-1997/98, In: CASTRO, J.L.; ITO, M.F. (eds.), $\mathbf{1 5}^{\mathbf{0}}$ Dia de

Campo de Feijão. Campinas, Instituto Agronômico, p.53-73. CARBONELL, S.A.M.; AZEVEDO FILHO, J.A.; DIAS, L.A.S.; GONÇALVES, C.; ANTONIO, C.B., 2001. Adaptabilidade e Estabilidade de Produção de Cultivares e Linhagens de Feijoeiro no Estado de São Paulo. Bragantia, 60(2): 69-77.

COSTA, A.S., 1965. Three White-fly Transmitted Virus Diseases of Beans in São Paulo, Brazil. FAO Plant Protection Bulletin, 13:3-12.

COSTA, A.S., 1975. Increase in the Populational Density of Bemisia tabaci a Threat of Widespread Virus Infection of Legume Crops in Brazil. In: BIRD, J.; MARAMOROSCH, K. (eds.), Tropical Diseases of Legumes. New York: Academic Press Inc, p.27-49. GALLO, D., NAKANO, O.; SILVEIRANETO, S.; CARVALHO, R.P.L.; BATISTA, G.C.; BERTI FILHO, E.; PARRA, J.R.P.; ZUCCHI, R.A.; ALVES, S.B.; VENDRAMIM, J.D., MARCHINI, L.C., LOPES, J.R.S., OMOTO, C., 2002. Entomologia Agrícola. Piracicaba, FEALQ, 920p.

MARTINS, J.C.; NAKAMURA, G., 2000. Efficiency of Seeds Treatments with Thiamethoxam to Control Bemisia argentifolii on Cotton Crop. In: INTERNATIONAL CONGRESS OF ENTOMOLOGY, 21., Foz do Iguaçu, Brasil, 2000. Abstract, Foz do Iguaçu, Book 1, p. 343.

POMPEU, A.S., CARBONELL, S.A.M.; ITO, M.F.; BORTOLETTO, N., 1999. IAC-Carioca Eté e IAC-Carioca Tybatã: Cultivares de Feijoeiro para o Estado de São Paulo. In: REUNIÃO NACIONAL DE PESQUISA DE FEIJÃO, 6., Salvador, 1999. Resumos expandidos. Salvador, p.382-383.

SILVA, R.B.; PAPA, G., 1998. Efeito do Thiamethoxan (Akitara) no Controle do Pulgão Brevicorine brassicae (Homoptera, Aphididae), na Cultura do Repolho. In: CONGRESSO BRASILEIRO DE 
ENTOMOLOGIA, 17., Rio de Janeiro, 1998. Resumos. Rio de Janeiro, livro 1, p.363.

WIESNER, P.; KAUFMANN, L.; SCHUERMANN, F.; KAYSER, H., 2000. Mode of Action of Thiamethoxam, a Novel Ligand of Nicotinic Acetylcholine Receptors - a Comparative Study of Neonicotinoids and Insects. In: INTERNATIONAL CONGRESS OF ENTOMOLOGY, 21., Foz do Iguaçu, 2000. Abstract. Foz do Iguaçu, Book 1, p.309. 